\title{
O ESTUDO DA GRAFIA DOS SUBSTANTIVOS EM XERENTE AKWE MRMẼZE
}

Valteir Tpêkru Xerente ${ }^{1}$

\section{RESUMO}

O objetivo deste estudo é apresentar um resultado concreto, ou seja, a escrita padrão sobre o processo da grafia dos substantivos em Xerente (Akwẽ Mrmẽze). Estaremos abordando especificamente os substantivos simples e compostos. A metodologia adotada na pesquisa ancora-se numa abordagem qualitativa, por meio de estudos bibliográficos, da análise documental de outros documentos produzidos a partir de programas e de ações voltadas para a educação escolar indígena Xerente, bem como da observação direta, do cotidiano e das práticas pedagógicas Akwẽ/Xerente, incluindo diálogos com moradores, entrevistas abertas, além das oficinas de leitura e escrita entre professores e alunos Xerente, além de outros instrumentos de pesquisa. O motivo da importância para a realização do estudo do processo da grafia dos Substantivos em Xerente Akwẽ Mrmẽze é que a maioria dos professores indígenas Akwẽ Xerente continua escrevendo do seu jeito, ou seja, sem levar em consideração um padrão ortográfico para a escrita da Língua Xerente.

PALAVRAS-CHAVE: Grafia. Língua Xerente. Substantivos em Akwẽ Mrmẽze.

\section{ABSTRACT}

The purpose of this study is to present a concrete result, that is, the standard writing on the spelling process of nouns in Xerente (Akwẽ Mrmẽze). We will be specifically addressing simple and compound nouns. The methodology adopted in the research is anchored in a qualitative approach, through bibliographical studies, documentary analysis, other documents produced from programs and actions focused on Xerente indigenous school education, as well as direct observation, daily life and of the Akwẽ/Xerente pedagogical practices, including dialogues with residents, open interviews,

1 Licenciado no Curso de "Educação Intercultural" (Ciências da Linguagem) pela Universidade Federal de Goiás e Mestrando em Letras, Ensino de Línguas e Literatura pela Universidade Federal do Tocantins (UFT). Professor da Educação Básica. Aldeia Karêhu, TO, Brasil. E-mail: valteir.xerente@hotmail.com. 
besides the reading and writing workshops between teachers and Xerente students, besides other research instruments. The reason for the study of the spelling process of the Nouns in Xerente Akwẽ Mrmẽze is that the majority of indigenous teachers Akwẽ Xerente continues to write in their own way, that is, without taking into account an orthographic pattern for the writing of the Xerente language.

KEYWORDS: Writing. Xerente language. Nouns in Akwẽ Mrmẽze.

\section{Introdução}

O presente artigo busca documentar a escrita padrão sobre o processo da grafia dos substantivos em Xerente (Akwẽ Mrmẽze). Este trabalho fornecerá ao leitor Xerente informações das regras ortográficas dos substantivos simples e dos substantivos compostos em língua materna Akwẽ Mrmẽze. Tem por objetivo discutir o sistema da escrita de nomeação e os significados de nomes próprios, nomes de animais, nomes de peixes e nomes de lugares do Povo Akwẽ, ou seja, concretizar ainda mais as estruturas dos nomes tradicionais. Pretendo contribuir para fortalecer a minha cultura, junto ao processo de ensino nas escolas indígenas Akwẽ.

O objetivo principal dessa pesquisa é o fortalecimento da língua e da cultura tradicional do meu povo Akwẽ. Sinto-me honrado de estar fazendo parte desse povo guerreiro. Para tanto, serão analisados os documentos referentes a esse processo, produzidos principalmente pelos linguistas que documentaram a língua materna do povo Xerente (Akwẽ). Pensado desta forma, a coleta de dados para a investigação da língua Akwẽ se baseará nas práticas de trabalho de campo presentes na literatura linguística: a) verificação e processamento dos dados ouvidos e elicitados ainda nas escolas e nas aldeias; b) Gravações, em áudio e vídeo, CDs digitais, de palavras, de textos narrativos sobre atividades cotidianas, de aulas dadas por professores e alunos indígenas, de relatos de viagens, sobre os tempos antigos, os mitos, as lendas e os rituais, como forma de registro da ortografia dos substantivos Xerente.

Portanto, temos como meta levar essa proposta da escrita padrão em Akwẽ Mrmẽze para os professores e alunos Xerente das escolas do povo Akwẽ começarem a trabalhar a escrita padrão Xerente com os conhecimentos voltados para a própria realidade 
sociocultural, na qual estão inseridos. Para essa prática, percebemos a necessidade de um trabalho de professor indígena interligado com a escola e com a aldeia, onde são ensinados os conhecimentos da cultura Akwẽ Xerente para crianças e jovens.

Por essa razão, escolhi esse tema para trabalhar na minha linha de pesquisa de mestrado "Agrafia dos Substantivos em Xerente (Akwẽ Mrmẽze)": Uma Proposta visando ao estabelecimento de regras ortográficas dos substantivos simples e substantivos compostos, a fim de promover estudos sobre a grafia dos substantivos em Xerente.

\section{Nomes próprios e pintura corporal Xerente}

Para o Povo Akwẽ Xerente, o nome não representa somente o nome, vai além do nome. Principalmente o nome masculino que traz consigo um grande significado, o respeito, a identificação do indivíduo na metade de clã. $\mathrm{O}$ nome feminino Akwẽ tem sua organização um pouco diferente dos nomes masculinos. Como por exemplo, o ritual da nominação feminina é mais doméstico, porque os anciãos e os homens não saem da aldeia, esse ritual é realizado somente dentro da aldeia, simbolizando na cultura as atividades domésticas, que é mais dentro da aldeia. O ritual ou cerimônia de nominação masculina/ ambâ, kwatbremĩ nĩsi é fora da aldeia, indicando que a atividade masculina é mais fora da aldeia, ou seja, representa roça, caça, pesca e outras atividades.

Por isso, os homens entram na mata e ficam acampados lá, cantando os cânticos em coletiva durante os dias que ficam dentro da mata, ou seja, até chegar o dia e a hora da cerimônia de batismo, que é realizado no pátio da aldeia, localizado no centro da aldeia. Com isso, a importância do nome significa muito na coletividade, na individualidade e na sociedade envolvente, nas práticas culturais e até mesmo no convívio cotidiano da pessoa.

Para os Akwẽ, cada nome possui seu significado e sua importância para cada indivíduo, por exemplo, o nome que a pessoa tem não é somente para indicar ou marcar a pessoa. Mas para a introdução da festa de nominação dos meninos, costuma-se sair os nomes Waikwadi e Brupahi. O nome Waikwadi vem do peixe pacu e Brupahi, do nome andorinha.

Além da importância dos nomes próprios, uma das coisas que nos levam a pensar são os significados dos nomes, ou seja, o que eles 
representam, pois, a maioria dos nomes está ligada com as coisas da natureza, nas quais muitos nomes são de animais, de peixes, de aves etc. Mas, o que mais nos impressiona é a beleza que os nossos nomes têm por si, ao recebermos um nome em Akwẽ, sentimos um grande orgulho de receber um nome verdadeiro, ou seja, que nos identifica como Akwẽ e mostra o amor que temos por nossa cultura e pela natureza. Na organização e nas distribuições de nomes próprios masculinos, os Akwẽ possuem dois sistemas para serem seguidos sem fugir da linha. Primeiro passo: os nomes são organizados por metades; segundo passo: os nomes são agrupados por clãs.

Para entendermos melhor essa organização social Akwẽ, deixo uma explicação bem clara, os Xerente são uma sociedade dualista. O grupo todo está dividido em duas metades interdependentes, possuindo, cada uma delas, três clãs distintos. Todo indivíduo Xerente pertence, obrigatoriamente, a uma ou à outra metade e esta identificação é recebida hereditariamente por parte do pai. A pintura clãnica dos Xerente se dá por parte de pai desde antigamente até na atualidade. E assim foram montadas as figuras em formas de pinturas corporais de seus respectivos clãs, conforme descreveremos abaixo:

A primeira pintura mostra a organização da metade daqueles que se pintam em círculos, composta por três clãs: $\boldsymbol{k u z} \hat{\boldsymbol{a}}$ - fogo, $\boldsymbol{k b a z i}$ - algodão e krito - mangaba.

A segunda figura mostra a organização da metade daqueles que se pintam em listras, composta por três clãs, wahirê - talo de buriti - İsake - algo que tem listra e krãiprehi - cabeça vermelha.

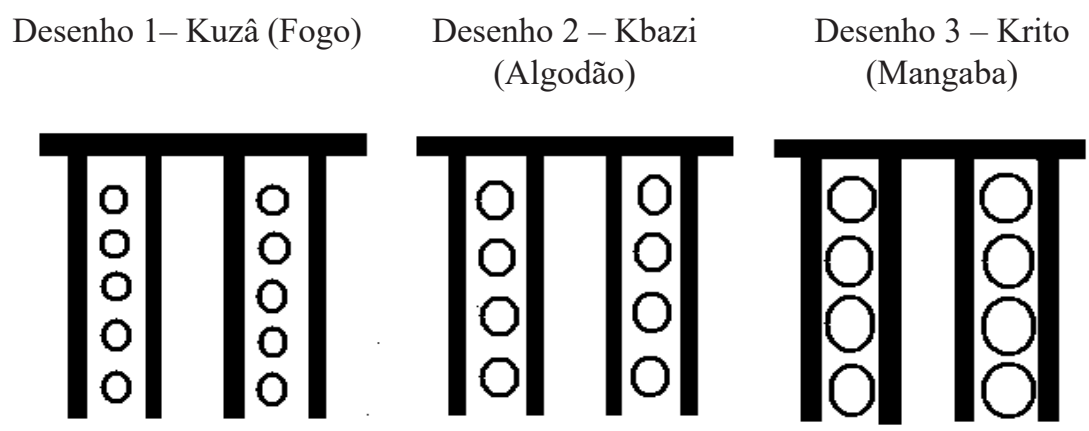

Fonte: Valci Sinã (2016). 


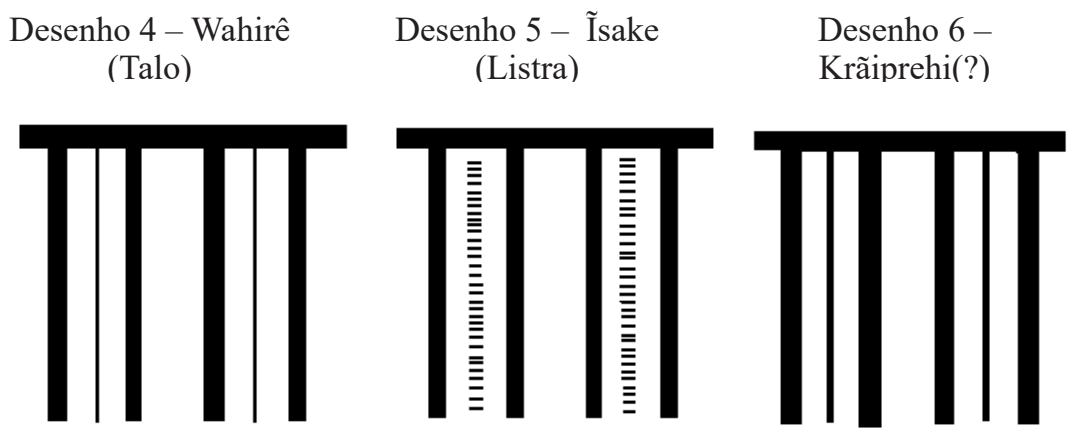

Fonte: Valci Sinã (2016).

Queremos também apresentar alguns exemplos de nomes próprios Akwẽ, conforme foi mencionado no texto acima, que cada nome pertence a uma metade da pintura, ou seja, do clã.

Exemplo1: Srêmtôwẽ, Kumnãse e Prase - pertencem à metade dos círculos.
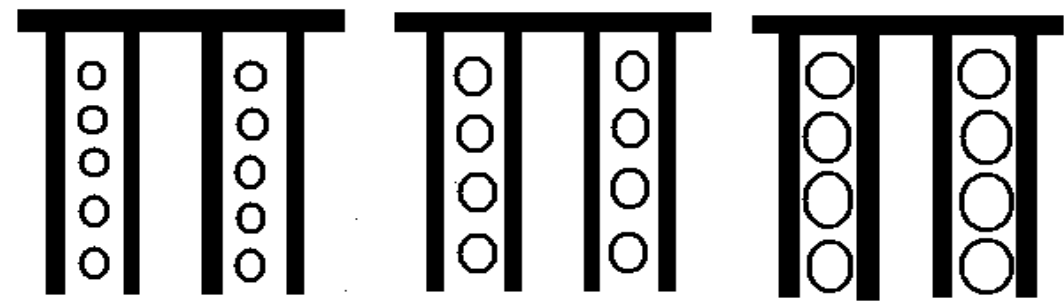

Exemplo2: Pnĩkudâ, Wawẽkrurê e Romtêpre - pertencem somente à metade de listras.
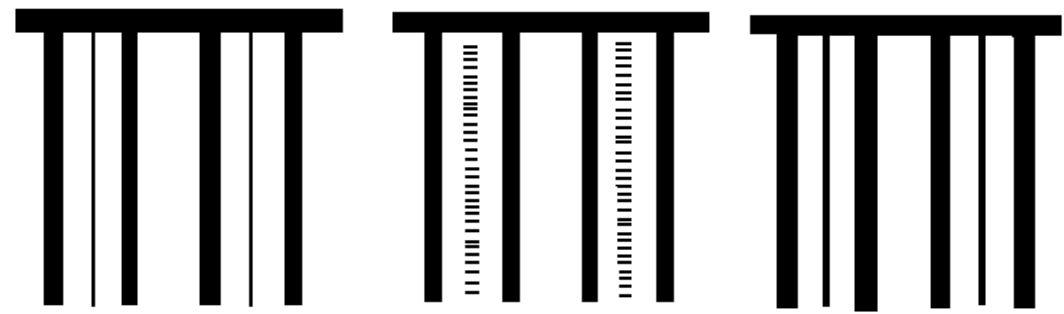
Portanto, a nomeação ou doação de nomes não deve ocorrer de qualquer forma, ou seja, a pessoa não deve nomear o filho conforme sua vontade própria. O filho ou o pai tem, por sua vez, a obrigação de seguir a linhagem do clã de seu pai, para não fugir da organização sociocultural de nosso Povo. A pessoa tem de conhecer os nomes da sua metade e de seu clã, pois caso surja alguma dúvida na escolha do nome do filho, ele deve procurar um ancião de seu clã ou um dos anciãos do clã oposto da outra metade.

\section{A escrita dos nomes de lugar, rios e peixe em Akwẽ}

Com base no nosso estudo da grafia de substantivo Xerente, mostraremos algumas definições da descrição de nomes de lugares da região do povo Akwẽ. São escritos juntos todos os elementos constituintes dos seguintes termos compostos por mais de uma palavra:

\section{Nomes Compostos em Xerente}

Srêmtõwẽ, Prase, Krtitmõwẽ, Dakmãnãrkwa, Datopskukwa, Wakedi, Brupahi, Sibâdi, Wakrtidi etc.
a) Nomes de Peixes
Exemplos:
Tpêbâ, Tpêkrãipo, Suwaratomzdakrenẽ, Tpêkatopre etc.
b) Todos os topônimos se tornam nomes específicos de lugares, rios etc.

Exemplos:

Nrõzawi, Kripre, Kuĩwdêpisi, Warewdêhu, Sakrêpra, Mrãiwahâ, Ktẽkakâ, Hêspohurê, Ssuirêhu, Kâwawẽ, Kâwakmõrê etc.

Observação: Quando um topônimo formado por várias palavras é usado de modo geral, os componentes da designação são escritos isoladamente uns dos outros, por se tratar de uma frase. Porém, quando o mesmo topônimo se torna o nome de um lugar específico, esses componentes são escritos juntos. 
Exemplos:

Ware wdê hu buritiraneira (lugar onde há muitos pés de buritirana)

Warewdêhu nome da aldeia Novo Horizonte

Hêspo hurê bananeiralzinho (pequeno lugar onde há muitos pés de banana)

Hêspohurê nome da aldeia Zé Brito

Nrõtom wdê hu najazeiro (lugar onde há muitos pés de najá)

Nrõtomwdêhu nome da aldeia Baixão

kâ wra kurerê rio de águas correntes e escorregadias

Kâwrakurerê nome da aldeia Brejo Comprido

Kri pre casa vermelha

Kripre nome da aldeia Salto

Kâ wawẽ rio grande

Kâwawẽ nome do Rio Tocantins

Quando um lugar determinado toma um topônimo por nome e lhe acrescenta alguma qualidade ou especificidade a mais, essa qualidade é escrita separadamente, por se tratar de uma modificação.

Exemplo:

Kâ wahâ

'água fria/ qualquer rio de água fria'

Kâwahâ 'nome do ribeirão Água Fria'

\section{Reflexões Finais}

Este estudo da grafia do substantivo Xerente é uma das primeiras pesquisas que estão sendo realizadas por um falante nativo, ou seja, por um Akwẽ. Sabe-se que não é uma tarefa fácil a de trabalhar com a escrita da língua, principalmente quando se trata de uma escrita padrão. Assim, este trabalho é um primeiro passo para 
nós, enquanto estudantes, seja do curso de Licenciatura Intercultural Indígena, sejam nos Programas de Pós-Graduação. Acreditamos, no entanto, na importância desse estudo e da pesquisa da escrita de nomes da língua Xerente para o conhecimento e preservação da nossa cultura e língua materna.

Acreditamos também que este estudo poderá auxiliar os professores Akwẽ na sua prática diária que está relacionada ao ensino da escrita e especialmente na grafia da língua Xerente. Portanto, estamos confiantes que este estudo poderá contribuir muito, principalmente para aqueles que querem estudar o processo de ensino da escrita de língua materna Akwẽ, configurando um processo de extrema importância para a manutenção linguística e cultural das tradições que nos cercam desde os primórdios de nossa sociedade.

\section{Referências}

KRIEGER, Guenther Carlos. Dicionário Escolar: Xerente-Xerente; Português-Xerente. Rio de Janeiro: Junta de Missões Nacionais da Convenção Batista Brasileira, 1994.

SIQUEIRA, Kênia Mara de Freitas. Aspecto do Substantivo na língua Xerente. Dissertação de Mestrado em Linguística. Goiânia: UFG/Faculdade de Letras, 2003.

MATTOS, Rinaldo de. Língua Xerente: Como se lê e como se escreve. Material não publicado.

SINÃ, Valci. Nomes próprios masculinos e femininos do povo Akwẽ Xerente e os significados dos nomes. Monografia de Aperfeiçoamento/Especialização em Cultura e História dos Povos Indígenas. Fundação Universidade Federal do Tocantins, 2016.

Recebido para publicação em abril de 2018.

Aceito para publicação em junho de 2018. 